\title{
PARA UN DIÁLOGO INTERRELIGIOSO CADA VEZ MÁS NECESARIO FRENTE A LA INTOLERANCIA Y LA VIOLENCIA
}

\author{
For an increasingly necessary interreligious dialogue in the face of intolerance and violence
}

\author{
Victorino PÉREZ Prieto ${ }^{\mathrm{I}}$
}

\section{Resumen}

Las religiones han nacido para ser fuente de paz, iluminación y liberación. Pero su realización histórica ha estado y está marcada por dinámicas de agresión y confrontación, de violencia e intolerancia destructiva del otro. Esta es la situación más problemática a la que la religión está llamada a responder de manera efectiva, lo que exige más que en ningún otro momento de la historia un auténtico diálogo interreligioso por la pluralidad de nuestras sociedades actuales y de nuestro mundo globalizado. Este diálogo, que es más que la simple tolerancia, tiene unos presupuestos que vienen marcados por el reconocimiento de que todas las religiones son verdaderas porque son caminos de salvación; por ello, tienen una parte de la Verdad, que es una, pero que no poseen en exclusiva ninguna de las religiones. Dios es siempre más grande de lo que puede decir de él cada religión. Huyendo del sincretismo y la confusión, ya que el diálogo se lleva a cabo a partir de las distintas identidades, cada religión debe reconocer que es un camino diferente para la consecución del único fin. Por eso, es necesario un dia-logos como reconocimiento de que nuestras verdades particulares (logos) deben estar siempre en camino (dia) en la búsqueda de la única Verdad.

Palabras clave: Religiones; Intolerancia; Diálogo; Ecumenismo; Interreligiosidad; Sincretismo; Verdad; Espiritualidad; Secular; Nuevas-formas-de-religión.

1 Doctor en Teología por la Universidad Pontificia de Salamanca y Doctor en Filosofía por la Universidad de Santiago de Compostela., España. Fue profesor en las Universidades de Santiago de Compostela, A Coruña y La Salle-Madrid, España, y en la Universidad de San Buenaventura-Bogotá, Colombia. Miembro de la Asociación de Teólogos Juan XXIII, el Seminario Galego de Educación para a Paz, Centro Interculturale Raimon Panikkar Italia (CIRPIT), Red Iberoamericana de Estudiosos de Raimon Panikkar (RIAP) (miembro fundador). Correo electrónico: vitope@outlook.es 


\section{Abstract}

Religions were born to be a source of peace, enlightenment and liberation. Yet, their historical realization has been and is still marked by dynamics of aggression and confrontation, of violence and destructive intolerance of the other. This is the most problematic situation to which religion is called to respond effectively. This requires more than at any other time in history an authentic interreligious dialogue for the plurality of our current societies and of our globalized world. This dialogue, which is more than simple tolerance, has certain presuppositions that are marked by the recognition that all religions are true because they are ways of salvation; therefore, they have a part of the Truth, which is one, but which none of the religions exclusively possess. God is always greater than any religion can say about him. Fleeing from syncretism and confusion, since the dialogue is carried out from the different identities, each religion must recognize that it is a different way to achieve the only goal. That is why a dia-logos is necessary in recognition that our particular truths (logos) must always be on the way (dia) in search of the only Truth.

Keywords: Religions; Intolerance; Dialogue; Ecumenism; Interreligious; Syncretism; Truth; Spirituality; Secular; New-forms-of-religion.

\section{Introducción}

Este trabajo ha nacido de una reflexión personal que hace el autor sobre el imprescindible diálogo ecuménico e interreligioso en la actualidad. Una reflexión sencilla pero madura, realizada tras años de investigación y publicaciones del propio autor sobre un tema querido para él y trabajado en su teología, porque lo considera una conditio sine qua non para hacer teología en el siglo XXI: hacerla desde la propia tradición cristiano-católica, pero en un diálogo constante con las otras religiones. Considero que hoy no se puede hacer teología mirando solo hacia dentro, a los hermanos que comparten Iglesia y vivencia religiosa; no se puede hacer teología sin olvidar los propios presupuestos de teólogo cristiano y católico, pero en atención a la experiencia y la reflexión que aportan las otras religiones desde sus propias tradiciones y experiencias actuales.

Por el carácter más personal de la reflexión, este trabajo no abunda en referencias científicas y en una bibliografía abundante, que el autor ha dejado ya reflejada en sus anteriores publicaciones, sobre todo en su libro La búsqueda de la armonía en la diversidad: El diálogo ecuménico e interreligioso desde el Concilio Vaticano $I^{2}$ al que se alude en varias ocasiones para evitar digresiones. Es un trabajo elaborado a partir de unas preguntas fundamentales, que figuran muchas veces el los epígrafes.

Se parte del sentido que sigue teniendo la religión en el siglo XXI, a pesar de las críticas que se le ha hecho en los siglos anteriores hasta llegar a "profetizar" su desaparición, y se habla de lo que considero la

2 Este libro, publicado en España en 2014 y presentado en Colombia en la Universidad Pontificia Bolivariana de Medellín y en la sede de la Conferencia Episcopal en Bogotá, tiene numerosas referencias bibliográficas y doce páginas con la bibliografía consultada; el índice onomástico permite encontrar fácilmente esas referencias. 
artificial distinción entre creyentes y no creyentes. Se pasa luego a ver las situaciones problemáticas a las que debe responder la religión en el mundo contemporáneo para no quedar al margen de la turbulenta vida de las sociedades actuales, tanto de Occidente como de Oriente. A continuación, se responde a dos preguntas fundamentales para el diálogo interreligioso: ¿son verdaderas todas las religiones? Y si todas las religiones son verdaderas, ¿por qué ser cristiano?

Después, se abordan los requisitos para el diálogo interreligioso, se pregunta si es suficiente la tolerancia para la vivencia del diálogo y se apunta el rol necesario de los laicos en el diálogo ecuménico e interreligioso, muchas veces relegado por el diálogo hecho solo entre especialistas y responsables institucionales. Posteriormente, se anotan los riesgos que supone un diálogo ecuménico e interreligioso. Y se responde a otra pregunta fundamental para un diálogo interreligioso hecho desde el cristianismo: ¿es Cristo el Salvador universal?

A continuación, se indica brevemente la postura del papa Francisco ante el diálogo interreligioso. Y luego se reflexiona sobre el sentido del anuncio del Evangelio en un mundo lleno de religiones, y un tema no menos importante: el diálogo del Evangelio con la sociedad secular, que parece manifestar menos interés por la religión.

Finalmente, se hace un acercamiento a un tema en particular importante para la sociedad colombiana: el sincretismo religioso en Colombia y si es posible dialogar con las nuevas corrientes religiosas. Para cerrar con unas conclusiones.

\section{¿Tiene aún sentido la religión en el siglo XXI?}

La religión ha sido contestada en los últimos siglos como algo inútil y aun pernicioso para el ser humano, tanto para cada persona como para la misma sociedad en su conjunto. Así, lo hicieron Karl Marx y los otros maestros de la sospecha (Nietzsche y Freud); profetizaron que las religiones desaparecerían en el siglo XX como fruto maduro de la era de la razón, la ciencia y la lucha social por la liberación, frente al oscurantismo opresor de aquellas. Para estos maestros, la religión sería tan solo "una alienación" de hombres y mujeres oprimidos, superestructura ideológica que la clase dominante usaría para tener sometida a la clase dominada (Marx), la obra de "humanos inferiores" que no sabrían realizar su natural grandeza de "superhombres" (Nietzsche) o una "ilusión infantil"/"paranoia universal" (Freud).

Cuando las relaciones humanas fueran "razonables" y "transparentes", con el advenimiento del socialismo, desaparecería "el velo místico de la religión", escribió Marx en El capital, su obra más conocida. Particularmente tuvo éxito su frase de que la religión es "el opio del pueblo"; una expresión que conviene situar en su contexto, leyendo todo el párrafo que escribió, para no ser mal interpretada y manipulada, como ha ocurrido miles de veces:

La miseria religiosa es la expresión de la miseria real y la protesta contra la miseria real. La religión es el suspiro de la criatura oprimida, el alma de un mundo sin corazón, lo mismo que es el espíritu de las situaciones desprovistas de espíritu. Es el opio del pueblo [...] La crítica de la religión es la crítica del valle de lágrimas [...] La crítica del cielo se transforma en critica de la tierra. (Marx, 1970) 
Hace ya tiempo que no tiene sentido el desprecio que manifestaron la modernidad y los "ilustrados" por lo religioso, como algo irrelevante para la liberación de la humanidad. La religión ha sido y es fuente de utopía y compromiso liberador para millones de personas. Particularmente, la historia de tantos mártires cristianos en las luchas por los derechos humanos de los más pobres e indefensos de los pueblos de América Latina en los últimos cincuenta años es un claro testimonio; Marx no es justo al generalizar el juicio de esta, tildándola solo de base de la superestructura opresora de la sociedad, en particular de la fe cristiana. Así lo reconocía hace años un experto en marxismo:

Marx tendría que admitir hoy [...] que en la religión se advierten dos vertientes: una ideológica [...] que ha servido de base para que las clases dominantes desdibujen el cristianismo primigenio, y otra positiva, liberadora, representada por la presencia del cristianismo moderno en teorías y prácticas progresistas, en las luchas contra la opresión, en la defensa de los derechos humanos, etc. (Bermudo de la Rosa, 1982)

De este modo, la religión sigue teniendo sentido hoy día, como siempre lo ha tenido y lo tendrá, porque el ser humano es esencialmente religioso. Es un homo religiosus, la religión es un constitutivo antropológico de toda persona, aunque cada cual vive su dimensión religiosa de manera diferente. La religión no solo no ha muerto con los avances del siglo XX, sino que, como la zarza ardiente, permanece muy viva en el siglo XXI. Así lo afirma un sociólogo de la religión tan respetado como Peter Berger (2002): en el actual contexto, resulta tentador centrarse en la forma en que la religión es usada para legitimar los más horrendos crímenes y, quizá, sentirse tentado a recordar aquellos pensadores de la Ilustración que concebían cualquier religión como algo perjudicial. Esto conduciría a una imagen muy falseada. La religión constituye, ante todo, parte de las vidas cotidianas de millones de personas corrientes, totalmente distanciadas de actos violentos. Tenemos que desterrar la idea de que modernidad y declive de la religión son fenómenos inexorablemente relacionados.

Tradicionalmente, se suele hacer la distinción entre creyentes y no creyentes, y así diferenciar a los que profesan una religión de los que no, que parece heredera de la vieja y discriminadora distinción entre fieles e infieles. Sin embargo, esta clasificación no es del todo exacta. Todo ser humano es creyente (tiene fe en sí mismo, en los demás, en unos valores concretos, en el mańana..., en Dios) y, en cierto sentido, es religioso, ya que se encuentra religado a la Realidad, ${ }^{3}$ aunque no se confiese seguidor de una religión específica e, incluso, de ninguna. Si bien cada persona religiosa concreta la manera en que adopta su fe en un conjunto de creencias, credos, tradiciones y ritos, que dan forma a las religiones y los grupos religiosos que conocemos. Aquel que no pertenece a ninguno de estos grupos establecidos también posee su sistema particular de creencias.

3 Es conocida la etimología de la palabra religión, que proviene del término latino religio, compuesto por el prefijo re y el verbo ligare. En esta perspectiva, la religión estaría relacionada con la acción de religar, con Dios y con toda la Realidad. 


\section{Situaciones problemáticas a las que debe responder la religión en el mundo contemporáneo}

La situación más problemática a la que la religión está llamada a responder de manera efectiva es hoy la intolerancia y la violencia. Las religiones han nacido con el fin de ser fuente de paz, iluminación y liberación. Con todo, aún en pleno siglo XXI, la realización histórica de las religiones está y ha estado marcada por dinámicas de agresión y confrontación. Esta desafortunada situación nace siempre de la intolerancia que impide reconocer que la verdad está también presente en el otro, no solo en mí. Si yo soy consciente de que tengo parte de la verdad, pero de que tú también posees una parte de ella, no solo estaré en condiciones de tolerarte, sino de abrirme a un diálogo mutuo y enriquecedor contigo. Este es el primer paso para la realización de la paz entre las religiones.

Además, un problema grave al que tienen que hacerle frente las religiones en la actualidad es el olvido de la espiritualidad. La fe ha sido encajonada a lo largo de la historia en un conjunto de dogmas cerrados que ensombrecen la esencia de la religión; una esencia que está en la experiencia religiosa, el encuentro con el Misterio, con una Divinidad personal o no personal. Y es en la experiencia espiritual profunda en que todas las religiones pueden hallar su punto de convergencia. El único lugar en el que podemos encontrarnos los creyentes de todas las religiones y las personas no religiosas que buscan vivir con intensidad y honestidad su existencia es en la espiritualidad, la mística, la interioridad. Ese lugar es el camino de la salvación o liberación cristianas, semejantes a la realización o la iluminación orientales; las tres palabras: espiritualidad, mística e interioridad, vienen a expresar lo mismo, aunque los puristas dirían que se trata de "intensidades" distintas. Hoy, el término espiritualidad, y cada vez más el de mística, es reivindicado como la experiencia religiosa más profunda y auténtica; y aun para muchos se presenta como oposición a la religión establecida, con sus credos, ritos y estructuras jerárquicas, que dificultarían una auténtica experiencia mística. Incluso, se habla del "agotamiento" de la religión y un resurgimiento de la espiritualidad más allá de ella. Por eso, no solo se habla de espiritualidades religiosas, sino también de espiritualidades laicas (Andrés y Esteban Garcés, 2019). En un mundo secularizado, la gente busca un tipo de espiritualidad que le permita entenderse a sí mismo y abrirse al encuentro fraterno con las otras personas y con el mundo. Si las religiones son capaces de garantizar esto, la situación de decadencia institucional pasa a un segundo plano.

Raimon Panikkar, ${ }^{4}$ maestro y amigo, solía decir que la epidemia más grande del mundo es la superficialidad. Superficialidad tiene que ver con vivir en la superficie de la Realidad, no ver en profundidad esa realidad, no pensar mucho, en oposición a una perspectiva filosófica y estética más "profunda"; tiene que ver también con lo ético y lo espiritual, con una manera de ver el mundo y estar en el mundo, comprometido o ausente. Tiene que ver con vivir de manera inconsciente, no consciente de lo que la Realidad es. El budismo enseña que en la comprensión y el conocimiento está la esencia del amor: "Con la plena consciencia, vemos que la otra persona sufre, y es justamente esto lo que nos motiva a hacer algo

4 Raimon Panikkar Alemany (1918-2010), fue un filósofo, teólogo y escritor español, cuyo trabajo ha sido calificado de un puente entre Oriente y Occidente. Entre su producción bibliográfica, se cuentan más de 80 libros y más de 1000 artículos. Tuve una gran amistad con él, reflejada en mis escritos; he publicado varios libros: Más allá de la fragmentación de la teologia, el saber y la vida: Raimon Panikkar; Dios, hombre, mundo: La Trinidad de Raimon Panikkar y Diccionario panikkariano, y más de 20 artículos sobre él. 
para que no sufra" (Nhât, 2001). El conocimiento en profundidad, la comprensión de la Realidad "es la esencia misma del amor" (pp. 35 y 36).

Las religiones están llamadas a ofrecer a la sociedad contemporánea la experiencia de la Realidad en una perspectiva de profundidad. Esta intuición es ciertamente una muestra de sabiduría, ya que, aunque los problemas que aquejan hoy día al mundo tengan muchos rostros, todos ellos encuentran su punto de partida en la visión superficial y materialista de la realidad. El sabio, en virtud de su desarrollo religioso y espiritual, descubre que la realidad es una sola y, en consecuencia, todos nosotros estamos unidos en una interrelación constante y constitutiva. Los seres humanos lo somos en relación; es la relación la que nos hace personas.

En la medida en que lo que le pasa al otro, a la naturaleza y al cosmos me afecta de manera directa, no es aceptable que yo tome una actitud indiferente ante los problemas de los demás. Por eso, la persona espiritual se caracteriza por buscar la justicia social, la paz y la armonía con la naturaleza y el cosmos. Pero estas cualidades no son producto exclusivo de la religión/las religiones, aunque pienso honestamente que ellas son las que han garantizado esta búsqueda de manera privilegiada en sus distinta tradiciones. De hecho, vemos que las personas profunda y auténticamente religiosas están comprometidas en su totalidad con el ejercicio de la solidaridad y la igualdad. Pensemos, por ejemplo, en Francisco de Asís, Mahatma Gandhi o Martin Luther King.

\section{¿Son verdaderas todas las religiones?}

Todas las religiones son verdaderas en cuanto caminos por los cuales las personas realizan su proceso de salvación; una salvación que lleva a meta final, que es una y única, como la Realidad en su profundidad. Ahora bien, son verdaderas en distintos grados. Si partimos del hecho de que ninguna puede pretender poseer la verdad absoluta, ya que supondría que sería capaz de abarcar la totalidad del Misterio infinito de la Divinidad, hay que sostener que cada una de las religiones tiene una parte de la verdad; y no todas en el mismo grado. Panikkar solía decir que cada religión tiene parte del todo y que ese todo se hace presente en la parte. Lo dice con unas expresiones latinas: pars pro toto y totum in parte et per partem (Pérez, 2016, pp. 225-226).

Ilustraré mi punto de vista con una metáfora. La Verdad es como la cumbre de una montaña; las religiones se asemejan a los distintos caminos que han sido trazados a lo largo del tiempo para llegar a esa cumbre. El ser humano se acerca a la Verdad, que no es otra que Dios/la Divinidad misma, por distintas vías; cada una de ellas es válida para conducir hacia la Verdad. El poeta español Antonio Machado escribió sabiamente: “¿Tu verdad? No, la verdad. Y ven conmigo a buscarla. La tuya, guárdatela” (Machado, 1973, "Proverbios y cantares", LXXXV). Esta frase sintetiza los presupuestos básicos para entender la validez de las religiones y el valor de su búsqueda.

\section{Si todas las religiones son verdaderas, ¿por qué ser cristiano?}

Muchos cristianos se preguntan ¿por qué seguir siendo cristiano si todas las religiones son verdaderas y salvan? La respuesta es sencilla y compleja a un tiempo. En primer lugar, somos cristianos porque consideramos 
que el camino hacia la salvación, la iluminación, la verdad y la liberación lo encontramos en la persona y el mensaje de Jesús de Nazaret, el Cristo de Dios, su Palabra, su manifestación única en la historia humana. Pero nuestra realidad está muy condicionada por el lugar en que nacemos, por nuestra familia, nuestros maestros y las gentes que nos han rodeado a lo largo de nuestras vidas. Por eso, otras personas en distintos lugares y circunstancias encuentran este sendero de realización existencial en el mensaje de Buda, Confucio, Lao-tsé, Krisna, Mahavira, Muhammad, la experiencia hindú del advaita, la cábala, los maestros hasidíes, los maestros sufíes, etc.

Los cristianos creemos que en Cristo se halla la plenitud de la Verdad y, por ende, todo lo que signifique desarrollo en el ser humano, como acabo de decir. Al confesar esta convicción, nos tomamos en serio las palabras del Evangelio, cuando el autor sagrado pone en boca de Jesús aquella afirmación de "Yo soy el camino, la verdad y la vida" (Jn 14, 6). Estamos seguros de que la plenitud de la salvación se ofrece en Cristo, a quien consideramos, no con poca osadía, que es Dios hecho hombre, es decir, Dios metido en nuestra realidad material, histórica y limitada. Él es el mysterium coniunctionis entre el Cielo y la Tierra, lo divino, lo humano y lo cósmico, que gustaba decir Panikkar (1999, p. 221). Pero debemos reconocer humildemente que esa verdad no la poseemos en exclusiva y está presente, aunque de modo oculto, en otras tradiciones religiosas (Panikkar, 1970).

\section{Requisitos para el diálogo interreligioso: el rol de los laicos en el diálogo ecuménico e interreligioso}

El primer requisito para el diálogo interreligioso es entender la propia religión en la doble perspectiva de camino y fin, en lugar de asumirla simplemente como el instrumento para. El ser humano es profundamente dialogal. De hecho, toda la realidad está constituida por la relación y el diálogo. Pero es necesario reconocer la distinción entre el diálogo dialógico y el diálogo dialéctico que hacía Panikkar (Pérez, 2016, pp. 8993). El primero se realiza pacíficamente en el ágora del debate, con el único instrumento del diálogo, compartiendo humildemente la propia verdad con la que tiene también el otro. El segundo tiene lugar, a menudo violentamente, en la arena de la batalla, con las armas de la razón, que pueden ser tremendamente afiladas. Mientras que la naturaleza propia del diálogo dialéctico exige la victoria de una parte a costa de la derrota de la otra, porque tiene armas más poderosas y mayor poder, el diálogo dialógico se construye como un camino de compartir el logos de mí hacia ti y de ti hacia mí (dia-logos es el logos que camina), sin buscar una victoria; se hace a partir del convencimiento de que en este proceso de doble vía los dos crecemos en iluminación.

Pero un segundo requisito es evitar a toda costa el sincretismo y la confusión, ya que el diálogo se lleva a cabo a partir de las distintas identidades de cada uno. Cuando yo, cristiano, opto por dialogar con un hinduista, un budista, un musulmán o un miembro de cualquier otra religión, no abandono mi identidad, ni tampoco aspiro a que el otro deje de ser él. Ambos nos abrimos el uno al otro para enriquecernos mutuamente desde los tesoros provenientes de nuestras identidades particulares, en busca de la armonía que ya existe en el cosmos. Es la búsqueda de la armonía en la diversidad, como he titulado uno de mis 
libros, ya citado aquí (Pérez, 2014). ${ }^{5}$ La experiencia interreligiosa va más allá de reconocer la importancia que tiene el diálogo: demanda clarificar cómo lo entendemos y a dónde queremos llegar con él. En este sentido, la pretensión no puede ser acotadora ni limitante; la apertura al otro debe ser total.

Asimismo, es necesario saber que, aunque tú tienes una parte de la verdad y yo tengo otra parte de la verdad, la verdad es la Verdad, absoluta e inabarcable. Dadas estas condiciones de la verdad, es posible que nos perdamos en su búsqueda. Claramente, no es lo mismo ponerse en meditación trascendental en silencio, usar cristales de sanación, rezar el rosario, hacer una novena o celebrar la eucaristía. Todas las religiones han reconocido que existe una jerarquía de valores que aporta en mayor o menor medida al proceso de iluminación del ser humano. Así, en el diálogo, no es solo la persona como individuo la que se abre al otro, sino que también lo hace la comunidad, la tradición y, por ende, la misma revelación divina, que actúa en el interior de personas, comunidades y tradiciones.

Aquí hay que hacer una aclaración valiosa. A pesar de que la revelación de Dios ocurre tanto en el cristianismo como en otras religiones, no se puede homologar la revelación bíblica, y aun la de otras grandes religiones, con la que defienden muchos seudoprofetas o seudoiluminados.

El criterio para establecer la validez de una determinada religión es el modelo de vida que se desprende de ella. Los que más saben de religión, en cualquiera de las tradiciones, son los místicos. Por eso, no dudo en afirmar que la plenitud de la experiencia religiosa es la mística; que es, igualmente, la plenitud de la experiencia de la vida, como decía Panikkar (2005). En otro orden de cosas, la mística no pertenece exclusivamente a una sola religión, sino que es un patrimonio común de la humanidad. De ahí que el criterio de verdad se fundamente en la forma en que la religión da vida, es decir, ayuda a vivir. Desde mi perspectiva cristiana, el hecho de dar vida se manifiesta como la vivencia de amar y ser amado. La esencia del mensaje de Jesús es el amor incondicional de Dios, en cuanto que todos los seres humanos, por el acto de existir, somos sus hijos bienamados.

En el hinduismo, encontramos tres perspectivas distintas en el camino de la salvación. La unión con lo divino (Brahma), experiencia de unión no dual (advaita), se puede lograr por medio de un triple camino: el camino del conocimiento (jñana marga), el del amor (bhakti marga) y el de la acción (karma marga) (Pérez, 2019, pp. 121-123). Estas tres vías no son realmente contrapuestas o excluyentes sino

5 En este libro, se puede encontrar abundante bibliografía respecto del diálogo interreligioso. En particular, las aportaciones de Raimon Panikkar, entre otras: Los dioses y el Señor (1967); Il dialogo intrareligioso (que incluye su texto pionero "Las reglas del juego en el encuentro religioso", 1988); Sobre el diálogo intercultural (1990); La nueva inocencia (que incluye el hermoso texto "El sermón de la montaña en el diálogo intrarreligioso" y otros relevantes sobre el diálogo interreligioso, que él llama "ecumenismo ecuménico", 1993); Invitación a la Sabiduría (1998); Iconos del misterio (2000); El diálogo indispensable: Paz entre las religiones (2003). Pero también otros textos importantes sobre el tema como los de J. Dupuis, Jesucristo al encuentro de las religiones (1991), Hacia una nueva teología cristiana del pluralismo religioso (2000) y El cristianismo y las religiones (2002); el pionero y discutible de J. Hick-P. Knitter (eds.), The myth of Christian uniqueness: Toward a pluralistic theology of religions (1987) y el mucho más reciente de P. Knitter, Introducción a las teologías de las religiones (2007); o los de J. Melloni El Uno en lo múltiple: Aproximación a la diversidad y unidad de las religiones (2003) y A. Pieris, desde la perspectiva de Oriente, Liberación, inculturación, diálogo religioso: Un nuevo paradigma desde Asia (2001); y los de J. J. Tamayo Fundamentalismos y diálogo entre religiones (2004) y A. Torres Queiruga, Diálogo de las religiones y autocomprensión cristiana (2005). 
complementarias. Aunque con el pensamiento judeocristiano solo se conoce lo que se ama, y solo conoce realmente quien ama, es necesario un hieros gamos o matrimonio sagrado entre conocimiento y amor. Es sobre todo en el amor donde podemos adentrarnos en la profundidad de la Divinidad y soprepasar los límites impuestos por el conocimiento puro: si no se ama, no se conoce en profundidad. Ahora bien, en atención a que Dios es la Verdad, más aún, Dios es verdad, la religión ha de llevar a la experiencia del amor recíproco manifestado en la acción. Una religión que no lleve a la experiencia del amor y devenga la vivencia del odio es una perversión.

Por ello, debemos preguntarnos: ¡es suficiente la tolerancia para la vivencia del diálogo? La respuesta es clara: no es suficiente. La tolerancia es, solo, un primer momento en el diálogo interreligioso. Primum vivere deinde philosophare, decían los latinos con razón: lo primero es vivir, luego viene el filosofar, el pensar esa vida. Lo primero es respetarse y no atacarse y aun eliminarse los unos a los otros, como se ha hecho muchas veces a lo largo de la historia humana. Lo más importante es la experiencia vital de la tolerancia y la relación pacífica. Pero el verdadero diálogo interreligioso es mucho más que la mera tolerancia de los diferentes y de lo diferente; esto ocurre habitualmente en el vivir cotidiano, pues, de lo contrario, nos estaríamos destruyendo constantemente. Aunque viendo la violencia intolerante que nos traen cada día las noticias, esto ya no sería poco.

Pero lo importante es aceptar que, como decía antes, el otro tiene una parte de la verdad y que, en consecuencia, nuestro diálogo conduce a un enriquecimiento mutuo. Es imperativo, entonces, que yo me abra al otro, porque el otro es altera pars mei, otra parte de mí. Para que yo pueda ser plenamente yo, necesito del otro. No se trata de una condescendencia o un discurso romántico; para que mi persona se constituya, necesito de ti, de los otros. Igualmente, tú necesitas de mí, lo creas o no.

La persona no es el individuo que puede vivir aislado, es un núcleo de relaciones. Por eso, la repetida frase de hacerse a sí mismo (el dicho americano self made man) no es real, en realidad es una tontería: todos nos necesitamos unos a otros, nos desarrollamos y nos hacemos en nuestras relaciones con los otros. Esa necesidad del otro no supone esclavitud, dependencia o sumisión; al contrario, es relación en igualdad, enriquecimiento mutuo.

En el cristianismo, como en todas las religiones, no solo los maestros, los teólogos y los clérigos son importantes en el diálogo interreligioso, también los laicos cumplen un rol absolutamente fundamental en la Iglesia que, ante todo, es el Pueblo de Dios. Uno de los errores más comunes en la realización del diálogo es creer que este se debe llevar a cabo solo por entendidos: teólogos y mayormente clérigos varones, aunque últimamente las mujeres van teniendo un papel importante en ese diálogo (Pérez, 2014, pp. 142-56). Debe haber un diálogo entre el pueblo llano de las distintas tradiciones religiosas. De hecho, el diálogo es más fácil entre las bases que entre las cúpulas: la gente siempre ha entendido que los miembros de otras religiones no son demonios que deben ser rechazados. En esta perspectiva, la gente sabe bien hoy que quien es bueno lo es sin importar la religión a la que pertenezca.

De aquí se desprende la urgencia de buscar la "pureza de corazón”. Solo hay diálogo cuando existe un corazón sencillo, limpio y sin prejuicios. Mientras que los que tienen altas responsabilidades en las Iglesias y religiones amontonan dogmas y limitaciones, el pueblo se desenvuelve en otras esferas. En efecto, las relaciones ecuménicas han sido reales desde hace muchos ańos al margen de si hay acuerdo o no entre los jerarcas. En los países caracterizados por la pluralidad cristiana, como Alemania y Centroeuropa, tras 
dejar atrás años de conflictos, o por el pluralismo religioso, como la India, la interrelación es una realidad que no representa obstáculos o problemas; entre otras cosas, porque hay preocupaciones más importantes que solucionar.

\section{Los riesgos del diálogo ecuménico e interreligioso}

Sentando bien los requisitos para un verdadero diálogo, no deberíamos hablar de "riesgos" de un diálogo interreligioso o de un diálogo ecuménico entre cristianos. Pero estos riesgos los hay, precisamente, porque los presupuestos del diálogo no están bien sentados.

Sin duda, el principal riesgo del diálogo interreligioso es su degeneración en sincretismo. Tal y como sostenía Panikkar (1995), el sincretismo es un "esperanto religioso" que lleva a una superreligión; y nace a costa de la desaparición de las religiones. Esto es muy negativo, pues el sincretismo es la muerte de la diversidad y la riqueza religiosa; una riqueza proveniente de las diferencias que aportan las distintas religiones, que debe mantenerse a toda costa. Por eso, una cosa es decir que todas las religiones son verdaderas y otra muy diferente afirmar que todas ellas son iguales. En realidad, más bien todas las religiones son distintas, son caminos distintos, aunque pretendan alcanzar un mismo fin: la validez de las religiones no desdice su diferencia intrínseca. Como los seres humanos, el ser humano es único, de ahí la igualdad entre todos, pero los humanos somos diferentes, como se manifiesta en las distintas lenguas, culturas y religiones.

En el campo ecuménico, hacemos bien en orar por la unidad de los cristianos. Pero dicha unidad no quiere decir uniformidad: la Iglesia es una, pero esa unidad no es uniforme sino armónica en su diversidad; es la armonía en la diferencia. Estas diferencias se manifiestan en las distintas confesiones cristianas que expresan la riqueza histórica del único Cuerpo de Cristo que formamos todos los cristianos. En este sentido, la unidad de los cristianos no significa que todos los seguidores de Cristo deban someterse a la autoridad papal y su magisterio. De hecho, esa idea resulta ya del todo irrealizable, tal y como la historia se ha encargado de demostrarlo en diversos momentos (Pérez, 2014, pp. 92-91).

Además, si somos fieles al Nuevo Testamento, el deseo de una uniformidad viene a ser un pecado contra de la diversidad de carismas del Espíritu, como ha dicho genialmente Oscar Cullman (1986). Las distintas confesiones cristianas no son un perverso avatar histórico, aunque se haya pagado un alto precio en enfrentamientos, sino que son expresiones de la pluriformidad de carismas que el Espírito otorga a los bautizados para edificar la única Iglesia, como reconoció el Vaticano II (Pablo, 1964, n. 8). Aunque la diversidad no deja de lado la urgencia de continuar en la búsqueda de la única Verdad, que es la verdad de Cristo. En este marco de comprensión, el camino ecuménico que se ha realizado a partir del Concilio Vaticano II es magnífico.

En primer lugar, se han podido dejar atrás los enfrentamientos a muerte que protagonizaban los discípulos de Jesús; enfrentamientos que se han convertido en uno de los mayores escándalos del cristianismo a lo largo de su historia. En segundo lugar, se ha abierto el paso a un diálogo teológico-doctrinal que ha permitido llegar a acuerdos importantes respecto de temas fundamentales para el cristianismo. Tal es el caso, por ejemplo, de la Declaración conjunta sobre la doctrina de la justificación, firmada en 1999 en Augsburgo (Alemania) por parte de la Iglesia católica y la Federación Luterana Mundial. El hallazgo 
de puntos de encuentro entre todos los bautizados es, sin duda, una riqueza que no va en contra de las particularidades de cada una.

Desde una mirada más abierta, en el diálogo entre las tres grandes religiones monoteístas, se han convalidado metas compartidas ante la promoción de la paz mundial como reflejo del amor gratuito de Dios. Con las religiones orientales, los cristianos hemos crecido a partir del encuentro con experiencias de meditación trascendental y de una búsqueda de equilibrio con la naturaleza. Por su parte, budistas e hinduistas han asumido del cristianismo el compromiso radical liberador con los pobres y la justicia social.

El segundo gran riesgo del diálogo interreligioso es perderse en la búsqueda de la verdad. Hemos de ser conscientes de que la verdad no es relativa, aunque mi acercamiento o la interpretación que haga de ella sí lo es. Para realizar una búsqueda fiel y sincera, se necesita un trabajo en el cual estén incluidos el espíritu y la razón o, dicho en términos propios de la tradición oriental, se necesita armonizar las visiones que emanan del ojo contemplativo y del ojo racional. De hecho, el oculus carnis, oculus rationis y oculus fidei $i^{6}$ del que hablaban Hugo de san Víctor y san Buenaventura deben trabajar conjuntamente; solo es posible encontrar la verdad oculta cuando logramos que los tres ojos, ciencia-reflexión-contemplación, se abran y trabajen conjuntamente. Así pues, todas las religiones están en la obligación de proveer los medios suficientes para potenciar la búsqueda existencial del creyente de aquello que está más allá: Dios, la Divinidad, el Misterio, que es siempre más.

\section{¿Cristo Salvador universal?}

Aunque en atención a los distintos caminos de salvación que ofrecen las diversas religiones puede resultar polémico decir que Cristo es el salvador universal, creo que es así realmente, pero son necesarias ciertas aclaraciones, sobre todo en la actualidad, en este mundo tan legítimamente plural.

La salvación y mediación universal de Cristo es un elemento fundamental de la fe que abrazamos como cristianos. En palabras de Panikkar, Cristo es el mysterium coniunctionis, el misterio de la unión entre lo divino y lo humano, el nexo entre Dios y la Humanidad. Pero los cristianos no poseemos la plenitud de la persona de Cristo, o lo que es lo mismo: Cristo es más grande que los cristianos; no tenemos la propiedad exclusiva de Cristo y el hecho crístico. Por eso, debemos reconocer que la salvación de Cristo se realiza también en otras religiones, a través de unas mediaciones distintas de las que sostiene el cristianismo. El mismo Panikkar tiene un concepto que me parece genial a la hora de entender las dinámicas propias del diálogo interreligioso: los equivalentes homeomórficos (Pérez, 2016, pp. 108-110). Con esto, se quiere manifestar el hecho de que la experiencia salvífica de Jesús puede tener lugar en otras tradiciones religiones, con otras formas y conceptos, que superan lo que él llama un "cristianismo tribal", mediterráneo y eurocentralista. En esas religiones, se encuentran elementos que, aunque no son iguales a los que están presentes en el cristianismo, son también válidos. Yaveh, Dios, Alá o Brahama representan a la misma Divinidad, pero no son lo mismo, no se definen de la misma manera.

6 El ojo de la carne es el empírico, el ojo de la razón es el racional y el ojo de la fe es el contemplativo (Pérez, 2018, pp. 225-236). 
Pero esto no es lo mismo que el conocido cristianismo anónimo de Karl Rahner (1969) y Bernard Sesboué (1999). La diferencia estriba, principalmente, en que el jesuita alemán sostiene que los no cristianos, al actuar de manera homóloga a la propuesta axiológica del Evangelio, son cristianos anónimos, cristianos aún sin saberlo. Considero que esto no es correcto, ya que el cristianismo es una experiencia religiosa concreta con unos límites precisos. El mismo Panikkar, amigo de Rahner, solía contestar que él estaría dispuesto a aceptar que los budistas son "cristianos anónimos", cuando los cristianos estuvieran dispuesto a reconocer que son "budistas anónimos". La persona de Cristo supera las fronteras históricas de la religión cristiana; la salvación universal ofrecida por Él atraviesa todas las tradiciones filosóficas y religiosas de una manera que va más allá de la realización cristiana específica.

El cristianismo está en condiciones de tener la pretensión legítima de hallar su presencia en las demás religiones, siempre y cuando sea lo suficientemente humilde como para renunciar a sí mismo para lograr la salvación de todos los seres humanos. Me refiero a la propuesta de una kénosis del cristianismo que, si lo pensamos detenidamente, está realizada cabalmente por los místicos, ya que son ellos los que llegan hasta lo más profundo en la experiencia religiosa de la persona. El místico es consciente de la relatividad de las creencias cuando descubre la realidad profunda de la Divinidad. "Todo lo que ahonda converge", me gusta repetir. Es en la profundidad en que la concreción histórica de lo religioso pasa a un segundo plano, pero no porque el Uno (Dios) sea relativo, sino porque yo ser humano soy relativo. En este sentido, la plenitud de la verdad en Cristo es mucho más grande que las formulaciones sostenidas por el cristianismo, a pesar de sus dogmas geniales.

Afortunadamente, los cristianos siempre hemos sabido que el Misterio no es algo que pueda ser plenamente comprendido, es apofático, se mantiene oculto, y así debe ser aceptado. El Misterio es, más bien, algo que vamos descubriendo y comprehendiendo paulatinamente, conforme a la superación de las limitaciones humanas e históricas, pero que nunca llegamos a comprehender totalmente. Desde mi perspectiva, uno de los problemas fundamentales de la Iglesia y de la teología es estar convencidas de "saberlo todo". Debemos concienciarnos de que estamos en camino, en el largo camino de la búsqueda de la verdad. Si la verdad es histórica, forzosamente debemos aceptar que la reconocemos de manera procesual. Por eso, es altamente curativo reconocer los errores e identificar las contradicciones que pueden existir en las afirmaciones magisteriales.

\section{La postura del papa Francisco ante el diálogo interreligioso}

Cuando terminé mi libro La búsqueda de la armonía en la diversidad: El diálogo ecuménico e interreligioso desde el Concilio Vaticano II, tuvo lugar la elección del papa Francisco tras la desconcertante dimisión de Benedicto XVI. Ante las acciones sorprendentes que pronto Francisco comenzó a realizar, me vi en la necesidad de retocar el manuscrito de mi obra en el capítulo que se refería al repaso histórico de la actitud del Magisterio eclesiástico frente al diálogo ecuménico e interreligioso (Pérez, 2014, pp. 50-55). Ya desde sus primeros días, el pontífice latinoamericano se propuso lograr que ambos diálogos fueran una realidad eficaz en la Iglesia. Sus experiencias biográficas en Argentina le habían llevado a asumir existencialmente las consecuencias del encuentro y el diálogo con el otro, lo cual le permitió estructurar su pensamiento en una perspectiva singularmente ecuménica e interreligiosa. 
El hecho de que un papa dijera que Dios "no es católico" resultaba absolutamente único y sorprendente en la historia de la Iglesia. Él mismo precisó en una entrevista: "Dios es mi Padre, tu padre, nuestro padre"; Dios no es solo el Padre de los católicos, sino de todos los hombres y mujeres. Otra afirmación sorprendente de Francisco se refiere a su afirmación en la misma entrevista (la que le hizo el periodista laico italiano Eugenio Scalfari, publicada en La Repubblica el 1 de octubre de 2013) de que "el proselitismo es una estupidez". Es necesario diferenciar la misión, que es una exigencia del cristiano, que tiene su fundamento en compartir con los demás la riqueza de la experiencia de Jesús, del proselitismo, que busca convertir a todos a mi religión, sin respetar la riqueza y la verdad que hay en la suya. La evangelización tiene que ver más con el acto de conocerse y escucharse: “Tenemos dos oídos, pero una sola boca”, le oí a un misionero en una ocasión.

La revolución que sigue generando el papa Francisco ańos después, una verdadera primavera para la Iglesia, es una recuperación de los efectos que produjo en su tiempo la primavera que llevó a cabo Juan XXIII con la revolución conciliar. Retomando el pensamiento de Rahner, puedo decir que de la primavera eclesial de Juan XXIII hemos llegado a la primavera de Francisco, después de haber atravesado por el "largo invierno eclesial” de Juan Pablo II, que decía el gran teólogo católico. Gracias a Francisco, podemos respirar en la Iglesia un aire lleno de libertad, ilusión y esperanza. El papa intentó asumir el mensaje que guio la vida de Francisco de Asís: restaurar una Iglesia que amenaza ruina. Defiende que el cristianismo tiene aún mucho por decir a la sociedad, y trata de comunicárselo y hacerlo realidad, más en los "hospitales de campaña" de las afueras que en la seguridad interior. Espero de todo corazón que estas ideas se lleven a realizaciones concretas, que produzcan cambios profundos en el diálogo de la Iglesia con las otras religiones, puesto que hasta ahora nos movemos todavía en el terreno de las esperanzas y las propuestas.

\section{El sentido del anuncio del Evangelio en un mundo lleno de religiones: el diálogo del Evangelio con la sociedad secular}

Muchos contemporáneos se plantean si siguen teniendo sentido las misiones, el anuncio del Evangelio en un mundo cargado de religiones, tras haber aceptado el valor salvífico de estas. Creo que la repuesta es que sí tiene sentido, porque, como sostuve, la razón de la evangelización no es convertir a mi religión al hermano de otra religión, sino ayudarle en la apuesta por el amor y la compasión, de la que Jesús de Nazaret ha sido el más grande de los maestros, y el encuentro con el Misterio del que es el gran Maestro, porque "viene de Dios", como dijo genialmente Joseph Moing $(2005,2010)$. Todos los seres humanos debemos convertirnos, pero no a una religión específica, sino a un crecimiento en el espíritu y el amor. Chenu, el gran teólogo francés, dijo de Juan XXIII al día siguiente de su muerte: "Creo que en el pensamiento y la acción de Juan XXIII hay un denominador común: el sentido del diálogo, reconocer al otro como otro, amar al otro tal cual es, y no como un ser al que hay que conquistar; consentir que sea diferente frente a mí" (citado en Bosch, 1991, p. 41).

Al reconocer a Jesús como la plenitud de la verdad, descubrimos que el Evangelio es un mensaje insuperable, y que otros deben conocerlo para que puedan vivirlo, haciéndose cristianos o no. El Reino de Dios es más grande que la Iglesia. El Evangelio es la verdad más grande que han conocido los siglos. Recuerdo que en alguna ocasión Gandhi dijo que el mensaje de Jesús era el más excelso de todos; el problema para él era cómo lo expresaban y vivían los cristianos. 
Conscientes de lo anterior, los misioneros de hoy ya no tienen entre su objetivo primordial bautizar sin más a cualquiera que encuentren por el camino, sino anunciar, dar a conocer su persona y hacer realidad el mensaje liberador de Jesús de Nazaret. Más que hablar, el misionero se dedica a escuchar, a aprender de aquellos con los que comparte en sus viajes evangelizadores. Gracias al desarrollo de esa capacidad de escucha, el misionero está en condiciones de ejercer su derecho de dar a conocer aquello que ha experimentado como salvador y liberador. A partir de ese enriquecimiento mutuo, es viable salvar y liberar. Se entiende, entonces, que el Evangelio no es un compendio de doctrinas y dogmas, sino un camino y una práctica del amor: "Todos conocerán que son discípulos míos en esto: si tienen caridad entre ustedes" (Jn 13, 35). Por eso, los misioneros son los cristianos más respetados en el mundo secular.

Al hablar del diálogo del Evangelio con la sociedad secular actual, en la que mucho de nuestros contemporáneos han dejado de ser personas religiosas, lo primero que hay que decir es que, en realidad, el cristianismo está en las bases del proceso de secularización. El desarrollo de la fe en Jesús y su mensaje llevó a una desacralización de la naturaleza y del mundo, que estaba tan presente en las religiones del mundo antiguo, o lo que es lo mismo, llevó a la secularización, sobre todo en las sociedades occidentales. En atención a esto, el cristianismo no le puede tener miedo al mundo secular, tal y como nos lo enseñó Juan XXIII: "No tengáis miedo. Abrid las ventanas al mundo". Ocurre, entonces, un cambio significativo: ya no es que fuera de la Iglesia no haya salvación, como afirmó mucho tiempo la Iglesia (extra Ecclesiam nulla salus); es más bien que fuera del mundo no hay salvación (extra Mundi nulla salus); o la Iglesia está en el mundo y se desenvuelve sin miedo en el mundo o no tiene razón de ser. El jesuita y teólogo de la liberación Jon Sobrino añadiría aún más: fuera de los pobres no hay salvación (extra Pauperes nulla salus); nuestra relación con los pobres es fundamental en el anuncio del Evangelio y en la vida de la Iglesia.

El diálogo con el mundo secular significa que el cristiano experimenta la plenitud de su fe en cada circunstancia histórica por la que atraviesa. Lo que el creyente debe tener claro es lo que Panikkar denomina ontonomía (Pérez, 2016, pp. 2011-215), esto es, el respeto por las diferentes perspectivas de acercamiento a la Realidad (los tres ojos mencionados). La ontonomía significa que en la relación entre carne, razón y fe, o los argumentos empíricos, racionales y teológicos para conocer, ninguno es más que el otro. Esa relación tiene que ser de respeto y de complementariedad, respetando cada uno su campo, su categoría de conocimiento. En un panorama así, se vuelve lógico el hecho de que la Iglesia no tenga nada que objetar respecto de las explicaciones que la ciencia empírica ofrece en su análisis de la realidad material. Cuando la Iglesia se sitúa adecuadamente frente al mundo de la realidad empírica y científica, no tiene por qué haber conflicto.

\section{¿Es posible dialogar con las nuevas corrientes religiosas? Sincretismo religioso en Colombia}

El diálogo interreligioso debe ser realizado con todos, incluso con los que no quieren dialogar, como es el caso de tantas sectas cerradas que se multiplican en nuestras sociedades actuales; en particular, en la sociedad colombiana con lo que se ha dado en llamar "Iglesias garaje". En los escenarios abiertos para dialogar, decía Panikkar, debe haber un asiento, incluso, para el intolerante. Con todo, no significa que se le permita imponer su opinión sobre los otros, aunque sí se le respete el derecho a hablar y ser escuchado. Cuando se ha dicho que la new age o las corrientes religiosas similares deben ser excluidas del diálogo, ha 
sido porque se les ha considerado como experiencias sincréticas que dificultan el sano compartir al anular las diferencias. Aun así, tenemos un reto por enfrentar.

De todas formas, hay que reconocer que los movimientos orientales aportan a la experiencia religiosa de Occidente una vivencia profunda de la espiritualidad. Si muchas de las Iglesias históricas se han ido vaciando paulatinamente, no es porque las personas no sigan siendo religiosas en el mundo de hoy, sino porque, en vez de encontrar en ellas la paz fundamental para alcanzar su desarrollo existencial y espiritual, se topan con un conjunto de leyes áridas que no les ayudan en su búsqueda espiritual. En la medida en que la espiritualidad tenga más fuerza en las grandes tradiciones religiosas, será posible que estas religiones encuentren con mayor claridad su espacio en el mundo.

Otro puente para establecer el diálogo con las nuevas corrientes religiosas está dado por la recuperación de la afectividad, tal y como lo han mostrado las Iglesias cristianas de nacimiento más reciente en América Latina. Formar parte de una religión implica la posibilidad de poder realizar mi fe en un grupo en el que yo sea importante. Desgraciadamente, las autoridades eclesiásticas han tenido un peso nefasto en el olvido de la dimensión de la Iglesia como Pueblo de Dios, como, afortunadamente, ha resaltado el Vaticano II. Por eso, el cristianismo no debe tener miedo al encuentro con las religiosidades contemporáneas.

Con los movimientos fundamentalistas que afirman que tienen la verdad absoluta, el diálogo resulta un poco más complicado. Estos grupos, como las "Iglesias garaje” en Colombia, parten de un presupuesto que va en contra del fundamento del diálogo, a saber: la convicción de poseer la verdad absoluta de modo único; una verdad incuestionable que viene de su líder. Por eso, el primer paso en el trato con ellos debe ser el amor, antes que la argumentación y la razón. Colocar la razón como inicio de la relación resulta inútil, ya que solo desemboca en una batalla de presuntas verdades carente de sentido. La carga afectiva de los fundamentalistas hacia la pureza de las doctrinas impide que se abran a una búsqueda compartida de la verdad. Sin embargo, es amor el que puede romper los muros e ir más allá del conflicto.

Lo siguiente por hacer, si hay cabida para tal cosa, es construir un marco que permita la comunicación de las distintas posturas personales y comunitarias de fe; la fe interiorizada a la par que el conjunto de creencias de la fe de la comunidad, su credo. En muchos casos, se llega fácilmente a la experiencia de la oración o la práctica conjunta. Solo será en un tercer momento en el que tiene lugar, en algunos casos, un crecimiento en la verdad dogmática.

En Colombia, hay un sincretismo, tal y como sucede y ha sucedido en el pasado en todas las sociedades, y posiblemente más en esta por una serie de circunstancias históricas, sociales y antropológicas. Considero que el sincretismo, aunque a veces puede ser inevitable y ha sido, en cierto modo, una ley histórica en lo que respecta al intercambio de culturas, es negativo en el sentido de que este no es enriquecedor, pues, al hacer una amalgama de todo, olvida las distintas identidades con sus riquezas particulares. La riqueza que emana de la experiencia interreligiosa se nutre de la escucha atenta a los demás a partir de las identidades particulares. Una escucha así genera aprendizaje de la verdad del otro y, al mismo tiempo, invita a una revisión de mis verdades personales, sin necesidad de olvidarlas o anularlas. En un proceso así, no hay algo sincrético, cosa que sí ocurre cuando se mezclan y confunden todos los elementos constitutivos de las religiones. 


\section{Conclusiones}

Es posible y necesario un auténtico diálogo ecuménico e interreligioso en nuestras sociedades plurales actuales, en nuestro mundo globalizado. Este diálogo, que es más que la simple tolerancia, tiene unos presupuestos que vienen marcados por el reconocimiento de que todas las religiones son verdaderas porque son caminos de salvación y tienen una parte de la Verdad, que es una, pero no está poseída en exclusiva por ninguna de las religiones. Dios es siempre más grande de lo que puede decir de él cada religión. La Iglesia tiene un mensaje salvador que transmitir, por fidelidad a Jesús de Nazaret, el Cristo de Dios, pero debe trasmitirlo con respeto hacia los otros y con amor, abierta sin miedo a lo que aportan las demás religiones, huyendo del sincretismo y la confusión, ya que el diálogo se lleva a cabo a partir de las distintas identidades; cada religión debe reconocer que es un camino diferente para la consecución del único fin.

\section{Referencias}

Andrés Suárez, E. y Esteban Garcés, E. (eds.) (2019). Hacia una teología de la interioridad. PPC.

Berger, P. (2002). Globalization and religion. Hedgehog Review, 4(2), 7-20.

Bermudo de la Rosa, M. (1982). Antología sistemática de Marx. Sígueme.

Bosch, J. (1991). Para comprender el ecumenismo. Verbo Divino.

Cullman, O. (1986). L’unité par la diversité. Cerf.

Machado, A. (1973). Poesías completas. Espasa-Calpe.

Marx, K. (1970). Contribución a la crítica de la filosofía del derecho en Hegel . En Anales franco-alemanes. Ariel.

Moing, J. (2005). Dios que viene al hombre. Vol. II: Del duelo al desvelamiento de Dios. Sígueme.

Moing, J. (2010). Dios que viene al hombre. Vol. II/1: De la aparición al nacimiento de Dios. La aparición. Sígueme.

Nhât Hanh, T. (2001). Bouddha et Jésus sont des frères. Reliés.

Pablo Obispo. Vaticano II. Lumen gentium. Nov 21 de 1964. http://www.vatican.va/archive/hist_councils/ii_vatican_ council/documents/vat-ii_const_19641121_lumen-gentium_sp.html

Panikkar, R. (1970). El Cristo desconocido del hinduismo. Marova-Fontanella.

Panikkar, R. (1995). Invisible harmony: Essays on contemplation responsability. Fortress Press.

Panikkar, R. (1999). La plenitud del hombre: Una cristofania. Siruela.

Panikkar, R. (2005). De la mistica: Experiencia plena de la vida. Herder.

Pérez Prieto, V. (2008a). Más allá de la fragmentación de la teología el saber y la vida: Raimon Panikkar. Tirant lo Blanch. Pérez Prieto, V. (2008b). Dios, hombre, mundo: La Trinidad de Raimon Panikkar. Herder. 
Para un diálogo interreligioso cada vez más necesario frente a la intolerancia y la violencia

Pérez Prieto, V. (2014). La búsqueda de la armonía en la diversidad: El diálogo ecuménico e interreligioso desde el Concilio Vaticano II. Verbo Divino.

Pérez Prieto, V. (2016). Diccionario panikkariano. Herder.

Pérez Prieto, V. (2018). Los tres ojos del conocimiento en San Buenaventura: de la reductio bonaventuriana al pensamiento complejo de Edgar Morin y la perspectiva cosmoteándrica de Raimon Panikkar. En J. C. Barrera y L. F. Benítez Arias (eds.), Perspectivas sobre el pensamiento de San Buenaventura de Bagnoregio y otros estudios (pp. 215-248). Universidad de San Buenaventura.

Pérez Prieto, V. (2019). La interioridad en las tradiciones religiosas no cristianas. En E. Andrés Suárez y C. Esteban Garcés (eds.), Hacia una teología de la interioridad (pp. 95-140). PPC.

Rahner, K. (1969). Los cristianos anónimos. En Escritos de Teología. Vol. 6: Escritos del tiempo conciliar. Taurus.

Sesboué, B. (1999). Karl Rahner y los cristianos anónimos. Selecciones de Teología, 25. 